\title{
Effect of Crosslinking Agents on Chitosan Microspheres in Controlled Release of Diclofenac Sodium
}

\author{
Vanessa L. Gonçalves, Mauro C. M. Laranjeira, Valfredo T. Fávere \\ Departamento de Química, UFSC \\ Rozângela C. Pedrosa \\ Departamento de Bioquímica, UFSC
}

\begin{abstract}
In this work chitosan microspheres were prepared by the simple coacervation method and crosslinked using epichlorhydrin or glutaraldehyde for the controlled release of diclofenac sodium. The effects of the crosslinking agents on chitosan microspheres over a 12-hour period were assessed with regard to swelling, hydrolysis, porosity, crosslinking, impregnation of diclofenac sodium (DS), and consequently to the release of DS in buffer solutions, simulating the gastrointestinal tract. The degree of swelling varied with the $\mathrm{pH}$ for glutaraldehyde chitosan microspheres (GCM) and epichlorhydrin chitosan microspheres (ECM). Partial acid and basic hydrolysis affected the swelling behavior of the GCM matrix. Release kinetics of diclofenac sodium from these matrices were investigated at $\mathrm{pH}$ 1.2, 6.8 and 9.0, simulating the gastrointestinal tract conditions. The results indicated that the release mechanism deviated slightly from Fickian transport.
\end{abstract}

Keywords: Crosslinking, chitosan, diclofenac sodium, microspheres, controlled release.

\section{Introduction}

The oral administration of pharmaceutical dosage forms is the more usual, convenient and comfortable route for active drug delivery to the body. An oral controlled release formulation is subjected to frequent changes of environment in the gastrointestinal tract. Thus, during transit it passes from the strongly acid gastric segment to the weakly alkaline intestinal part of the digestive system ${ }^{[1,2]}$.

A number of polymers have been investigated for the development of in situ gel-forming systems, due to the ability of these hydrogels to release an entrapped drug into aqueous medium and to regulate the release of such a drug by control of swelling and crosslinking ${ }^{[3,4]}$. These systems have gained attention in the search for improved patient compliance and decreased incidence of adverse drug reactions.

Chitosan, a cationic polymer combined by $\beta-1-4$ glucosidic linkage is the main product obtained from the alkaline deacetylation of chitin, a major structural polysaccharide found in crustaceans, insects and lower plants $^{[5]}$. Chitosan has advantages over polysaccharides due to its non-toxicity and biodegradability. For these properties, chitosan has been used as a matrix of microparticulate and crosslinked systems for the immobilization and release of $\operatorname{drugs}^{[6-8]}$. A broad review of preparation methods, crosslinking and system interactions has been carried out by $\mathrm{Kas}^{[9]}$.

The crosslinking reaction is mainly influenced by the size and type of crosslinker agent and the functional groups of chitosan. The smaller the molecular size of the crosslinker, the faster the crosslinking reaction, since its diffusion is easier. Depending on the nature of the crosslinker, the main interactions forming the network are covalent or ionic bonds ${ }^{[10]}$. Covalently crosslinked hydrogels present the crosslinking degree as the main parameter influencing important properties such as mechanical strength, swelling and drug release. Such gels generally exhibit $\mathrm{pH}$-sensitive swelling and drug release by diffusion through their porous structure ${ }^{[11]}$. Therefore, hydrogels based on covalently and ionically crosslinked chitosan can be considered as good candidates for the oral delivery of drugs ${ }^{[12]}$.

Concern over the disintegration of chitosan microparticles has led to their modification by crosslinking to make a rigid polymer for use as a core material in controlled drug release research ${ }^{[13-15]}$. For this purpose, a large number of studies on crosslinking with agents involving bonds with chitosan amine groups ${ }^{[16-18]}$ has been carried out. However, none study on hydroxyl group bonds has been reported.

Diclofenac sodium (DS), one of the most useful nonsteroidal anti-inflammatory (NSAID) agents, is a practically insoluble compound in acidic solution ( $\mathrm{pKa} 4.0$ ), however, it dissolves in intestinal fluid. Gastrointestinal effects commonly observed include gastritis, peptic ulcers and bleeding, hypersensitivity reactions and renal effects ${ }^{[19,20]}$.

Recently, a number of studies describing oral release formulations of diclofenac sodium (DS) have been

Autor para correspondência: Mauro C. M. Laranjeira, Departamento de Química, UFSC, CEP: 88040-900, Florianópolis, SC. E-mail: mauro@ qmc.ufsc.br. 


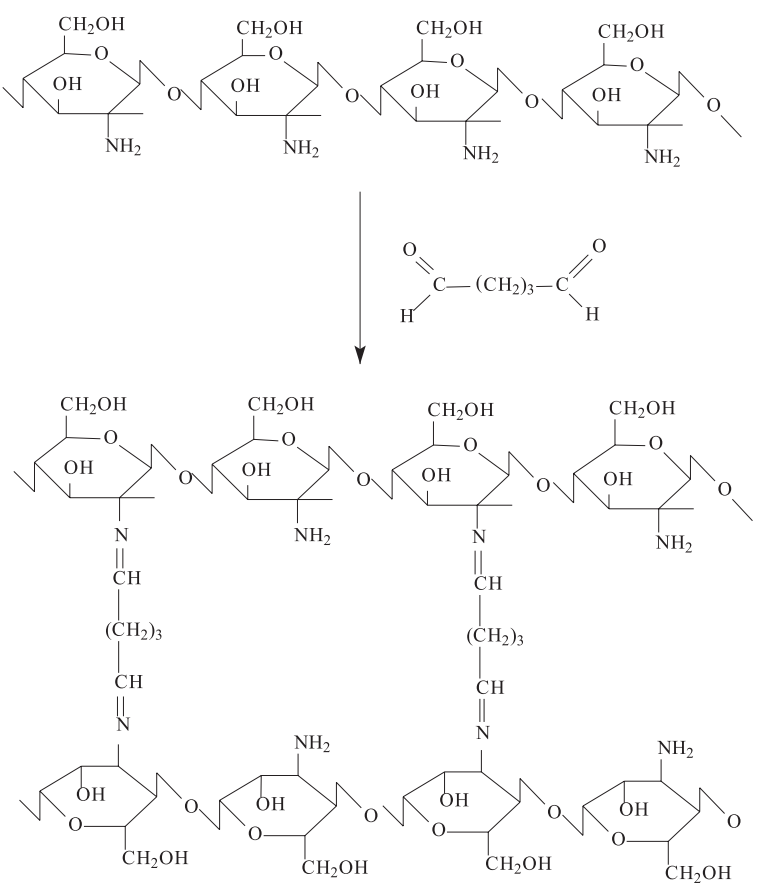

Figure 1. Crosslinking process of chitosan treated with glutaraldehyde.

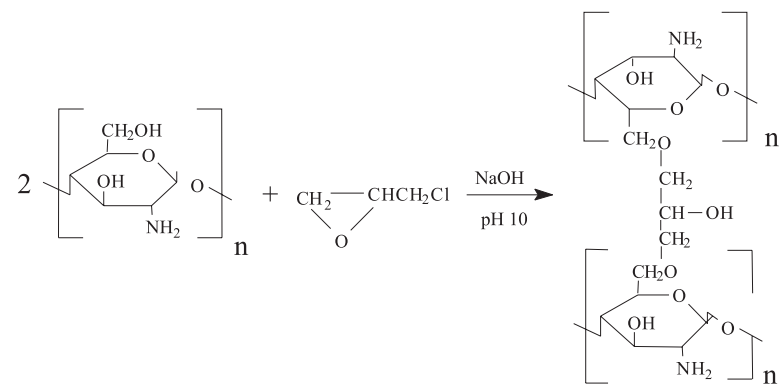

Figure 2. Crosslinking process of chitosan treated with epichlorohydrin

performed using as the matrix chitosan that has been reticulated covalently or ionically for the amino groups of the biopolymer.

Kumbar et al. prepared chitosan microspheres of diclofenac sodium with three different crosslinking methods, i.e. glutaraldehyde, sulfuric acid and heat treatment ${ }^{[16]}$

Shu and $\mathrm{Zhu}^{[21]}$, Açikgöz et al ${ }^{[22]}$ and Ko et a ${ }^{[23]}$ reported the use of complexation between polyanion tripolyphosphate and cationic chitosan by electrostatic forces resulting in a more homogeneous structure due to the more homogeneous crosslinking process. Murata et al. ${ }^{[24]}$ investigated the formation of a complex between chondroitin sulfate and chitosan and also the influence of this complex on the release of diclofenac sodium.

The objective of this work was to prepare crosslinked chitosan microspheres for the controlled release of sodium diclofenac using epichlorhydrin as an alternative to crosslinking agents that react with the amine groups of chitosan. For the sake of comparison, glutaraldehyde was used for crosslinking and aluminum was employed as an artificial pore forming agent to obtain porous microspheres and favor DS impregnation. The effects of the crosslinking agents on chitosan microspheres were evaluated in relation to swelling, hydrolysis, porosity, crosslinking, DS impregnation, and consequently to the release of sodium diclofenac in buffer solutions simulating the gastrointestinal tract in a 12-hour period.

\section{Materials and Methods}

\section{Materia/s}

Fine chemical-grade chitosan derived from shrimp-shell chitin following about $80 \%$ deacetylation was prepared according to the method described by Brossignac ${ }^{[25]}$ and powdered to 100 meshes before use ${ }^{[28]}$.

A sample of diclofenac sodium was obtained from Delaware Chemicals (Porto Alegre, Brazil), epichlorhydrin was supplied by Merck (Darmstadt, Germany). Methanol and glutaraldehyde were purchased from Vetec Fine Chemistry (Rio de Janeiro, Brazil). All other reagents were of analytical grade.

\section{Preparation of chitosan microspheres Epichlorhydrin crosslinked microspheres (ECM)}

A $4 \% \mathrm{w} / \mathrm{v}$ chitosan solution was prepared by stirring chitosan in $5 \% \mathrm{w} / \mathrm{v}$ acetic acid in a beaker with a magnetic stirrer. $0.5 \mathrm{~g}$ of magnesium silicate was then added to the solution in order to avoid aggregation of the microspheres.

The microspheres were formed as drops of the $4 \% \mathrm{w} / \mathrm{v}$ chitosan solution fell into a precipitation bath containing $2 \mathrm{M}$ $\mathrm{NaOH}$ solution, with drop formation being driven by a peristaltic pump. The solution containing the microspheres was continuously stirred for $1 \mathrm{~h}$ at $25^{\circ} \mathrm{C} .4 .9 \mathrm{ml}$ of epichlorhydrin were added to a suspension consisting of $10 \mathrm{~g}$ of microspheres immersed in $100 \mathrm{ml}$ of water and maintained at $50^{\circ} \mathrm{C}$ for $1 \mathrm{~h}$. Subsequently, $70 \mathrm{ml}$ of $0.1 \mathrm{M} \mathrm{NaOH}$ were added and the system was boiled for $2 \mathrm{~h}$. The microspheres were then sequentially rinsed in water, $0.1 \mathrm{M}$ hydrochloric acid, and $0.1 \mathrm{M} \mathrm{NaOH}$, and finally washed with water and dried.

\section{Glutaraldehyde crosslinked microspheres (GCM)}

A solution of $4 \% \mathrm{w} / \mathrm{v}$ chitosan in $5 \% \mathrm{v} / \mathrm{v}$ aqueous acetic acid was mixed with $0.5 \% \mathrm{w} / \mathrm{v}$ magnesium silicate and $0.03 \%$ $\mathrm{w} / \mathrm{v}$ aluminum powder. This solution was then added dropby-drop, using a peristaltic pump, to $300 \mathrm{ml}$ of $2 \mathrm{M} \mathrm{NaOH}$ solution. The precipitation occurred immediately upon contact with the medium, leading to the formation of the artificially porous microspheres due to the release of hydrogen in the reaction. The solution containing the microspheres was stirred continuously for $1 \mathrm{~h}$ at $25^{\circ} \mathrm{C}$, and the microspheres were then washed repeatedly with water and transferred to a 0.01 M EDTA solution where they remained for $20 \mathrm{~min}$ while stirring. Porous microspheres were immersed for $24 \mathrm{~h}$ in a known volume of an aqueous solution of glutaraldehyde $(2.5 \% \mathrm{w} / \mathrm{v})$, then washed with water and dried.

\section{Drug loading}

Wet crosslinked microspheres were immersed in a saturated solution of DS in methanol and water $(2: 1)$ for $24 \mathrm{~h}$. 
The drug-loaded microspheres were washed with cold, distilled water and dried.

An accurately weighed amount of loaded microspheres was crushed and kept under constant stirring in methanol for 20 min in order to extract the DS and the concentration of the solution was determined spectrophotometrically at $280 \mathrm{~nm}$. The quantification limit of diclofenac is $0.005 \mathrm{mg} / \mathrm{L}$. The reproducibility of the method was $\pm 2 \%$. The mean value of three determinations is reported.

\section{Swelling studies}

The swelling behavior of the crosslinked microspheres was explored by placing the dried samples in $50 \mathrm{ml}$ reservoirs containing simulated gastric fluid $(\mathrm{pH} 1.2)$, or simulated intestinal fluids $(\mathrm{pH} 6.8, \mathrm{pH} 8.0, \mathrm{pH} 9.0 \text { and } \mathrm{pH} 9.77)^{[26]}$. Reservoirs were shaken at $100 \mathrm{rpm}$ at $37^{\circ} \mathrm{C}$.

The weight of each swollen sample (Wt) was determined on an electronic balance after the removal of the microspheres from the solution and blotting.

The degree of swelling (DS) is expressed as the percentage of water in the hydrogel at any instant during swelling:

$$
\% \mathrm{DS}=\left(\mathrm{W}_{2}-\mathrm{W}_{1}\right) / \mathrm{W}_{1} \times 100
$$

In equation (1) $\mathrm{W}_{1}$ and $\mathrm{W}_{2}$ represent the weight of dry chitosan microspheres and the weight of wet chitosan microspheres, respectively.

\section{In vitro release studies}

To determine the quantity of drug released by the microspheres, known samples were set into a cell containing $50 \mathrm{~mL}$ of buffer solution ( $\mathrm{pH} \mathrm{1.2,} \mathrm{pH} \mathrm{6.8,} \mathrm{and} \mathrm{pH} 9.0)$. The samples $(1 \mathrm{~mL})$ were withdrawn at fixed time intervals and the solutions were replaced by fresh release media. All release studies were conducted in a shaker at $100 \mathrm{rpm}$ at $37^{\circ} \mathrm{C}$.

Release studies were carried out in simulated gastric fluid $(\mathrm{pH} 1.2)$ for $2 \mathrm{~h}$ followed by simulated intestinal fluids $(\mathrm{pH}$ 6.8 and $\mathrm{pH} 9.0$ ) for $4 \mathrm{~h}$ and $6 \mathrm{~h}$, respectively. The total residence time in buffer solution was $12 \mathrm{~h}$.

The drug concentration in each sample was then determined spectrophotometrically at $280 \mathrm{~nm}$. The cumulative percentage of drug release was calculated and the mean of three determinations was used in data analysis.

The amount of drug released at any selected time $\left(\mathrm{M}_{\mathrm{t}}\right)$ was calculated from the calibration curve in conjunction with the absorbance. The maximum weight available for release $\left(\mathrm{M}_{\infty}\right)$ was determined in the same way as $\mathrm{M}_{\mathrm{t}}$, the fractional release $\left(F_{t}\right)$ was then calculated as $F_{t}=M_{t} / M_{\infty}{ }^{[27]}$.

\section{Scanning electron microscope studies (SEM)}

Micrographs of the microspheres were taken with a scanning electron microscope (SEM, Philips XL,30) for visual inspection of the surface morphology and cross-sectional structure of the monolithic system, with and without the drug.

Samples were mounted on metal stubs using double-sided adhesive tape and vacuum-coated with gold film. Samples were then cross-sectioned using a blade to study the inner structure. The size was then determined as the average size of the microspheres in the micrographs (three micrographs each containing approximately 20-25 microspheres).

Qualitative Energy Dispersive X-ray Microscopy (EDX) was used to analyze whole and sectioned samples that had been recovered with gold at different points of the microspheres.

\section{Results and Discussion}

\section{Preparation and characterization of microspheres}

Chitosan microspheres were prepared by phase separation using the simple coacervation method. According to this method, the formation of microspheres results from a surface phenomenon due to the interaction between a polymeric solution (chitosan solution) and a coagulant medium (2M $\mathrm{NaOH}$ solution), which induces phase separation and yields a precipitated polymeric membrane. The precipitation of chitosan creates a chitosan-rich coacervated phase.

The microspheres were subject to a crosslinking process that consisted of treating them with epichlorhydrin or glutaraldehyde. This hardened the walls of the microspheres and reduced their porosity, resulting in a degree of crosslinking of $25 \%$ for ECM and $64 \%$ for GCM.

The crosslinking bifunctional agents used here bind to different reaction sites in the chitosan. The aldehyde groups of the glutaraldehyde form covalent imine bonds with the amino groups of chitosan, due to the resonance established with adjacent double ethylenic bonds via a Schiff reaction (Figure 1) while epichlorohydrin links through the carbon atoms, resulting in the rupturing of the epoxide ring and the removal of a chlorine atom (Figure 2) ${ }^{[28]}$.

The ECM and GCM microspheres are spherical structures with smooth surfaces. The average sizes were $0.962 \mathrm{~mm}$ and $1.295 \mathrm{~mm}$, respectively for ECM and GCM microspheres. The GCM cross-section presented in Figure 3a shows the great quantity of artificially formed pores, even after crosslinking. However, in Figure $3 b$ it can be seen that for epichlorhydrin there is matrix compaction after crosslinking.

Qualitative energy dispersive X-ray microanalysis (EDX) of the GCM was carried out in order to verify whether residual aluminum was present in the GCM ready for release. It was found that the aluminum added initially for the formation of microspheres was completely eliminated either through reaction with $\mathrm{NaOH}$, or through the process of chelation with EDTA. Moreover, microspheres obtained by this technique were non-tacky and non-sticky.

\section{Drug loading}

The impregnation process of the crosslinked microspheres was carried out by placing them into a solution of diclofenac sodium in a 2:1 water:methanol mixture. The quantity of drug impregnated was $210 \mathrm{mg} / \mathrm{g}$ and $440 \mathrm{mg} / \mathrm{g}$ for ECM and GCM, respectively.

The drug was dispersed uniformly in the polymeric monolithic systems. Figures $4 \mathrm{a}$ and $5 \mathrm{a}$ show the microspheres without drug, while Figures $4 \mathrm{~b}$ and $5 \mathrm{~b}$ show the impregnation 

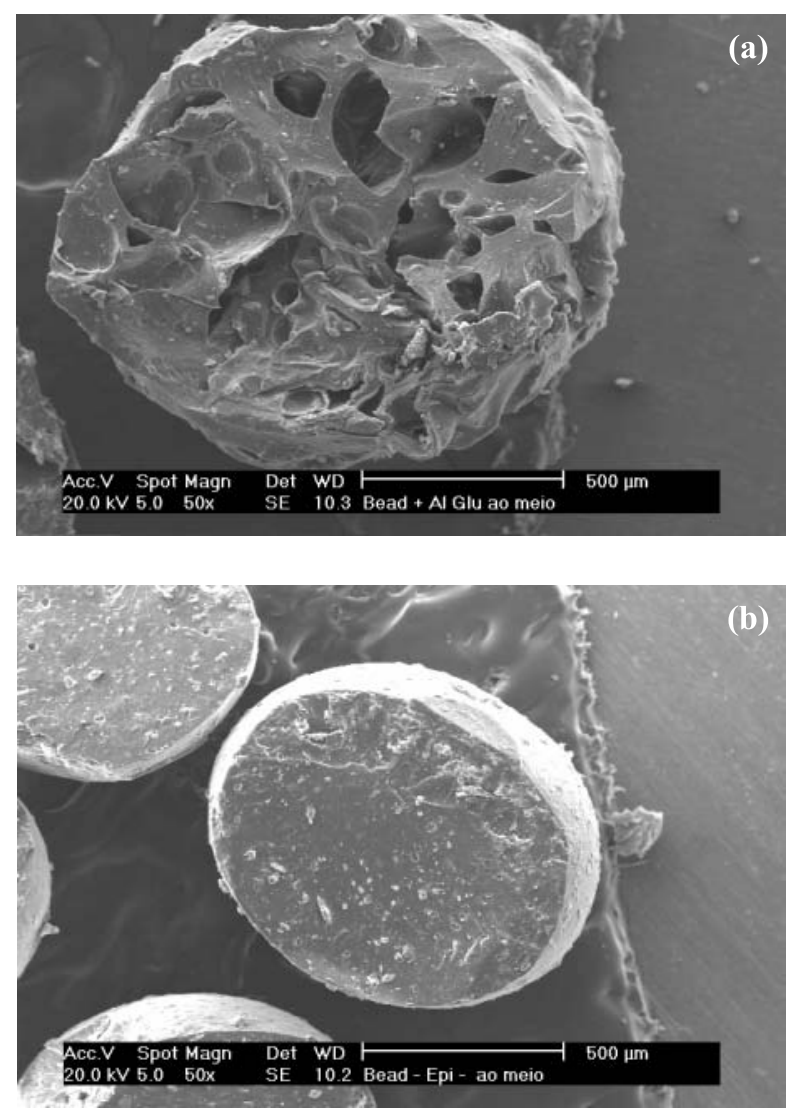

Figure 3. Scanning electron micrographs of cross-section of: (a) GCM microspheres; (b) ECM microspheres.

and uniform distribution of DS on ECM and GCM microspheres, respectively.

The difference in the quantity impregnated may be associated with the higher porosity of GCM formed by the addition of aluminum as the pore forming agent, facilitating the impregnation of a higher quantity of DS. For the impregnation method microspheres should be rigid and contain open pores. They should also be chemically and biologically inert and able to hold the impregnant inside the pores by capillary forces. The pores should be interconnected and open to the particle surface allowing full diffusion outward of the retained active ingredient ${ }^{[29]}$.

\section{Swelling studies}

In vitro swelling studies were conducted in simulated gastric fluid and in simulated intestinal fluids at $37^{\circ} \mathrm{C}$ and the degree of swelling $(\mathrm{Wt} \%)$ for each was determined gravimetrically. Plots of dynamic swelling of crosslinked microspheres, ECM and GCM, are given in Figures 6a and $6 \mathrm{~b}$, respectively.

The swelling mechanism at $\mathrm{pH}<6$ involves the protonation of chitosan amine groups and structure relaxation due to the repulsion of the polymeric chains, and the dissociation of secondary interactions followed by swelling ${ }^{[30]}$.

Secondary interactions, such as hydrogen bridges and hydrophobic interactions occur between acetylated units of chitosan and lead to a more solid-like gel if the degree of

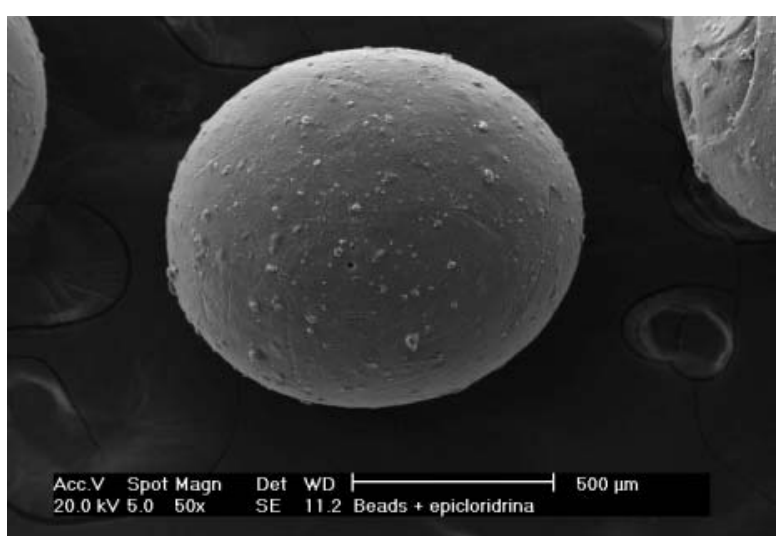

Figure 4a. ECM non-impregnated

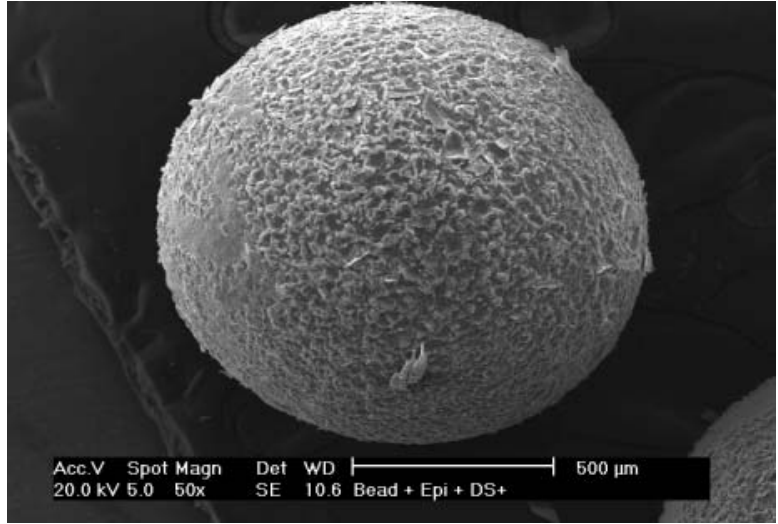

Figure 4b. Impregnated ECM

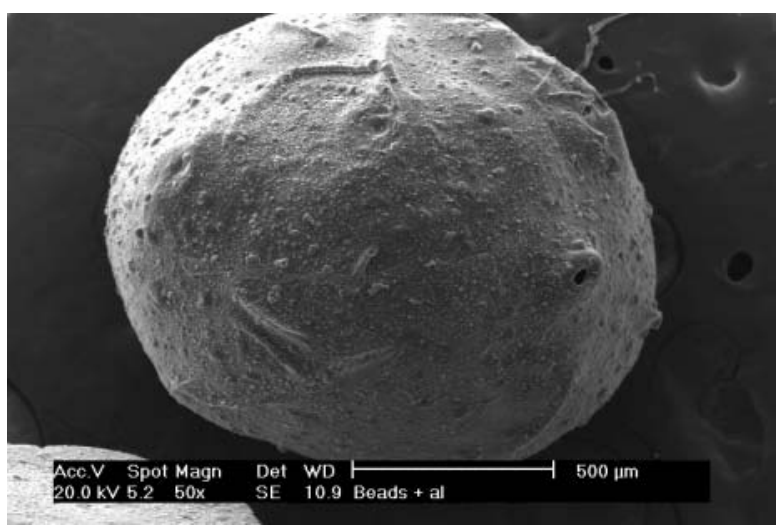

Figure 5a. GCM non-impregnated

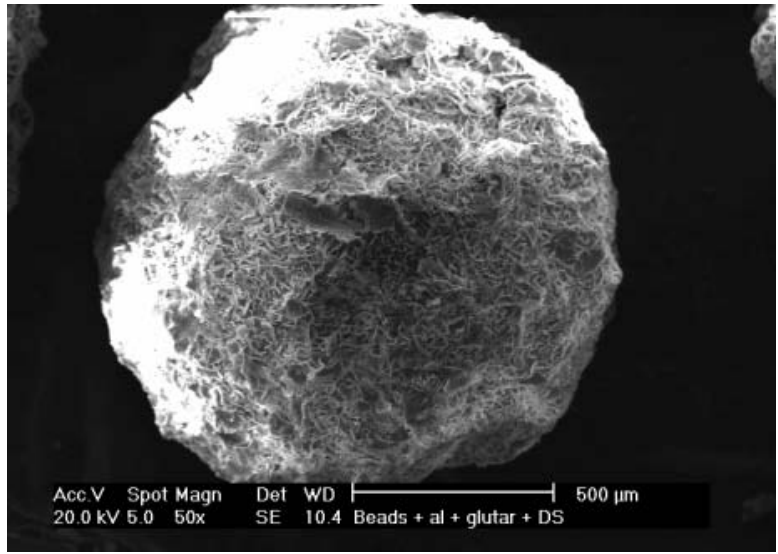

Figure 5b. Impregnated GCM 
deacetylation is low enough, but as the degree of crosslinking increases covalent bonds tend to become predominant ${ }^{[31]}$.

In this way it can be verified that there is greater swelling of microspheres crosslinked with epichlorhydrin, since this preferentially binds to hydroxyl groups in the polymeric chain leading to a large number of free amine groups. In the case of GCM the amine groups are occupied by the crosslinking and formation of a Schiff base.

Figure 6a shows the swelling behavior of ECM microspheres. Greater swelling can be observed at $\mathrm{pH} 1.2$ due to the protonation of the free amine groups, followed by $\mathrm{pH}$ 6.8, $\mathrm{pH}$ 8.0, $\mathrm{pH} 9.0$, and $\mathrm{pH}$ 9.77, a finding which also confirms that the crosslinked structure is chemically stable.

Figure $6 \mathrm{~b}$ shows the behavior of GCM microspheres, whose swelling increases up to $\mathrm{pH}$ 1.2. This is probably due to the partial acid hydrolysis of imine bonds of Schiff bases, which frees the chitosan amine groups again for gradual protonation.

In agreement with $\mathrm{pH}$ variations in the swelling study, the behavior of GCM microspheres was expected to be similar to that of ECM ones. Nevertheless, it was observed that at $\mathrm{pH} 9.0$ and $\mathrm{pH} 9.77$ swelling was greater than at $\mathrm{pH} 6.8$ and $\mathrm{pH}$ 8.0, with a probably less pronounced basic hydrolysis.
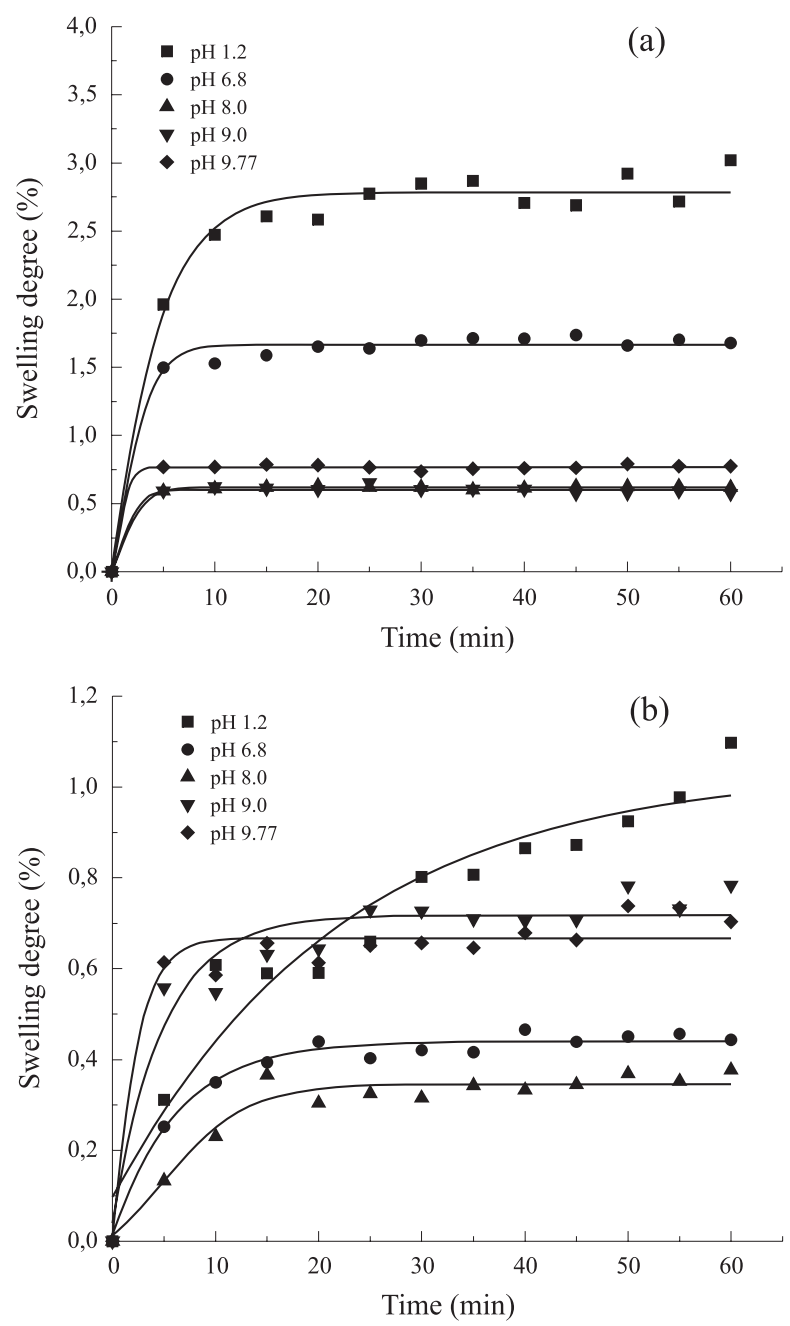

Figure 6. pH-dependent swelling behavior of: (a) ECM microspheres; (b) GCM microspheres.
The initially small swelling becomes constant since the protonation of these media is not favored.

The hydrolysis mechanisms of the Schiff bases in acid and basic aqueous media are known. $\mathrm{pH}$ profiles vs. partial hydrolysis speed constant for all Schiff bases show a lower reaction speed for $\mathrm{pH}>8.9$ and faster and stronger reactions for $\mathrm{pH}<3.5^{[32]}$. Another important factor that influences swelling is the degree of crosslinking of the microspheres. For GCM microspheres, the degree of crosslinking found was $64 \%$, which leads to a smaller degree of swelling, in comparison to that of ECM microspheres with a crosslinking extent of $25 \%$. Considering the effects of partial acid and basic hydrolysis of GCM microspheres, the degree of crosslinking is essential for preserving the integrity of the microspheres. If crosslinking were lower, hydrolysis would lead to the erosion of the microspheres with the resulting release of the drug at sites unfavorable to its absorption, and the consequent adverse gastrointestinal effects of DS.

Based on these results we can conclude that epichlorhydrin is an alternative crosslinking agent of chitosan microspheres used as drug carriers in oral drug release. The crosslinked product was chemically stable at all $\mathrm{pH}$ variations of the gastrointestinal tract, presenting neither partial acid nor basic hydrolysis with consequent erosion of the microspheres. In addition, crosslinking through the $\mathrm{OH}$ groups of chitosan leads to greater swelling, which favors drug release.

\section{In vitro release studies}

The DS release profiles of glutaraldehyde and epichlorhydrin crosslinked microspheres are shown in Figure 5. When analyzing the release profile of drugs such as DS, the dependence of solubility on $\mathrm{pH}$ must be taken into account. In fact, DS presents a higher solubility in water as a salt, but once the microspheres are in an artificial gastric solution $(\mathrm{pH} 1.2)$, DS is converted to its ionized acid form, which is very poorly soluble in water. In contrast, when the microspheres were immersed in a buffer solution of $\mathrm{pH} 6.8$, drug reconversion into soluble salt depends on dissolution speed. One means of verifying the bioavailability of DS in vitro is to submit it to varying $\mathrm{pH}$ and time conditions simulating the gastrointestinal tract. Thus, the microspheres (ECM and GCM) were first left for $2 \mathrm{~h}$ at $\mathrm{pH} 1.2$, considering that the drug would convert to its acid form, then switched to a favorable $\mathrm{pH}$ of 6.8 and left for 4 $\mathrm{h}$ for DS solubilization, and finally changed to $\mathrm{pH} 9.0$ for $6 \mathrm{~h}$ to complete the oral course. After $12 \mathrm{~h}$, about $25 \%$ of the DS had been released from glutaraldehyde crosslinked microspheres, while after the same time about $40 \%$ had been released from epichlorhydrin crosslinked microspheres. Release results in vitro are given in Figure 7.

On comparing the two systems ECM and GCM, it can be seen that ECM exhibited lower porosity, although they released almost the same quantity of the drug $(\cong 80 \mathrm{mg})$ as GCM, which had a higher porosity and load. The explanation for this may be that ECM has lower porosity, leading to the DS being impregnated more superficially. Moreover, their higher degree of swelling, facilitating the solvent access to 


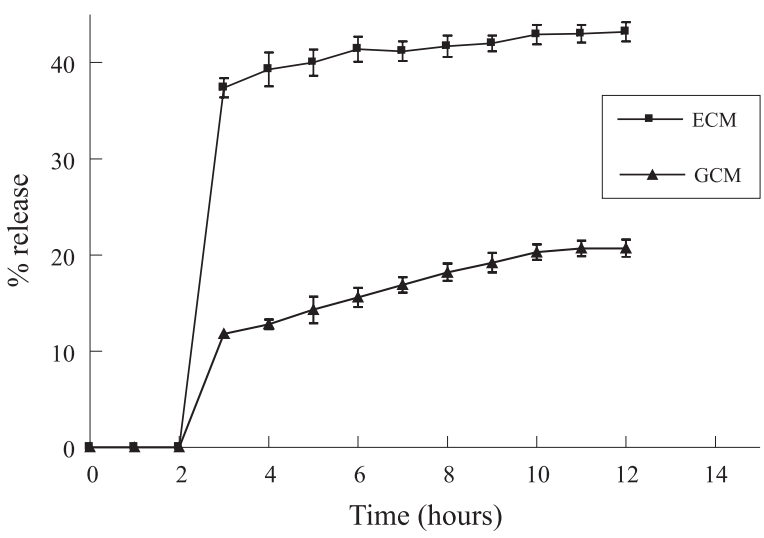

Figure 7. In vitro $\mathrm{pH}$-sensitive sequential release of DS from ECM and GCM microspheres in simulated gastric transit.

the drug incorporated in the polymeric matrix, increases contact with it and, consequently, allows greater release. For GCM, in spite of its high porosity and higher DS loading, the drug release was lower, since the degree of polymer swelling was lower, making solvent access difficult.

It is known that the release rate of drugs from hydrophilic matrices based on chitosan is affected by changes in $\mathrm{pH}$. The increase in release rates could be due to an associated increase in the fluid-filled cavities created by dissolution and diffusion of the drug particles near the surface, which in turn results in an increase in the permeability of the drug ${ }^{[33]}$.

Release of DS from microspheres depends upon the type of matrix and its rigidity. The release of the active agent from the matrix involves initial swelling followed by diffusion of the drug. In all the methods of crosslinking the drug release decreases with increased crosslinking ${ }^{[16]}$.

Several reports studying the effect of drug release have shown that the release of drug from the microspheres increases with an increase in drug content in the microspheres. However, the release of some drugs is reduced with an increase in drug content in the microspheres ${ }^{[34-35]}$. In these conditions, factors such as swelling, porosity, and drug solubility are determiners of drug release.

The release data for the microspheres were substantiated by fitting the cumulative fraction release data, $\mathrm{M}_{\mathrm{t}} / \mathrm{M}_{\omega}$, to an empirical equation:

$$
\mathrm{M}_{\mathrm{t}} / \mathrm{M}_{\omega}=\mathrm{kt}^{\mathrm{n}}
$$

Where $\mathrm{t}$ is the release time, $\mathrm{k}$ is a constant characteristic of the system and $\mathrm{n}$ is an exponent that characterizes the diffusional release kinetic mechanism ${ }^{[32]}$. For GCM and ECM matrices the n-values at $\mathrm{pH} 6.8$ were 0.79 and 0.81 , with a correlation coefficient close to 0.99 , respectively. In the case of microspheres, n-values $0.43<\mathrm{n}<0.85$ show non-Fickian diffusion, while $\mathrm{n}$ is equal to 0.43 for Fickian diffusion ${ }^{[36]}$. As could be seen the calculated $n$-values indicate that the release deviates from the Fickian mode.

\section{Conclusions}

Chitosan microspheres crosslinked with epichlorhydrin or glutaraldehyde behaved in different ways with regard to various aspects, such as the degree of swelling, and the amount of drug impregnated, and consequently released. The use of aluminum for the formation of artificial pores favored the impregnation of the microspheres with diclofenac, reaching values two-fold higher than those obtained in similar studies with crosslinked chitosan microspheres with amine group crosslinking agents. The degree of swelling varied for GCM and ECM. For GCM it was observed that partial acid and basic hydrolysis affected the swelling behavior of this matrix.

Dissolution studies over a $\mathrm{pH}$ range similar to that of the human gastrointestinal tract demonstrated that the rate of drug release from different matrices in simulated fluids ranged from rapid to slow depending on the type of matrix employed.

Both formulations gave a lower DS release at $\mathrm{pH} 1.2$, this being higher at $\mathrm{pH} 6.8$ due to the solubility of the DS, reaching values at $\mathrm{pH} 9.0(\cong 80 \mathrm{mg})$ similar to therapeutic concentrations (50 $\mathrm{mg}$ to $75 \mathrm{mg}$ ).

\section{References}

1. Thanoo, B.C.; Sunny, M.C. \& Jayakrishnan, A. - J. Pharm. Pharmacol., 45, 21-24, (1993).

2. Santos, H.; Veiga, F.; Pina, M.; Podczeck, F. \& Sousa, J. Int. J. Pharm., 246, 153-169, (2002).

3. Kumar, M.N.V.R. \& Kumar, N. - Drug Dev. Ind. Pharm. 27, 1-30, (2001).

4. Bravo, S.A.; Lamas, M. C. \& Salomón, C. J. - J. Pharm. Pharmaceut. Sci. 5, 213-219, (2002).

5. Felt, O.; Buri, P. \& Gurny, R. - Drug Dev. Ind. Pharm. 24, 979-993, (1998).

6. Tozaki, H.; Komoike, J.; Tada, C.; Maruyama, T.; Terabe, A.; Suzuki, T.; Yamamoto, A. \& Muranishi, S. - J. Pharm. Sci. 86, 1016-1021, (1997).

7. Paul, W. \& Sharma, C. P. - STP. Pharm. Sci. 10, 5-22, (2000).

8. Zhao, H-R.; Wang, K.; Zhao, Y. \& Pan, L-Q. - Biomaterials. 23, 4459-4462, (2002).

9. Kas, H. S. - J. Microencapsul. 14,689-771, (1997).

10. Ross-Murphy, S. B. - Polym. Gels. Netw. 2, 229-237, (1994).

11. Kanapczyk, J. - "Some aspects of chitosan hydrogel ointment base formulation", in: Chitin World, Karnicki, Z.S.; Brzeski, M.M.; Bykowski, P.J.; Woytasz-Pajak, A. (Eds), 512-519, (1994).

12. Basan, H.; Gümüsdereliolu, M. \& Orbey,T.- Int. J. Pharm. 245, 191-198, (2002).

13. Hamdi, G.; Ponchel, G. \& Duchêne, D. - J. Microencapsul. 18, 373-383, (2001). 
14. Knaul, J. Z.; Hudson, S. M. \& Creber, K. A. M. - J. App. Polym. Sci. 72, 1721-1732, (1999).

15. Gupta, K. C. \& Kumar, M. N. V. R. - J. App. Polym. Sci. 76, 672-683, (2000)

16. Kumbar, S. G.; Kulkarni, A. R. \& Aminabhvi, T. M. - J. Microencapsul. 19, 173-180, (2002).

17. He, P.; Davis, S. S. \& Illum, L. - Int. J. Pharmaceut. 187, 53-65, (1999).

18. Jameela, S. R. \& Jayakrishnan, A. - Biomaterials. 16, 769775, (1995).

19. Sallmann, A. R. - Am. J. Med. 80, 29-33, (1986).

20. Palomo, M. E.; Ballesteros, M. P. \& Frutos, P. - Drug Dev. Ind. Pharm. 23, 273-283, (1997).

21. Shu, X. Z. \& Zhu, K. J. - Int. J. Pharm. 201, 51-58, (2000).

22. Açikgöz, M.; Kas, H. S.; Orman, M. \& Hincal, A. A. - J. Microencapsul. 13, 141-160, (1996).

23. Ko, J. A.; Park, H. J.; Hwang, S. J.; Park, J. B. \& Lee, J. S. - Int, J. Phramceut. 249, 165-174, (2002).

24. Murata, Y.; Miyamoto, E. \& Kawashima, S. - J. Control. Release. 38, 101-108, (1996).

25. Broussignac, J. - Chin. Ind. Génie Chim. 99, 1241-1247, (1968).
26. Morita, T. \& Assumpção, R.M.V.-"Manual de soluções, reagentes e solventes: padronização, preparação e purificação". 2 $2^{\mathrm{a}}$ ed. SP: Ed. Blücher, (1993).

27. González-Rodrígues, M.L.; Maestrelli, F.; Mura, P. \& Rabasco, A. M. - Eur. J. Pharm. Sci. 20, 125-131, (2003).

28. Wan Ngah, W. S.; Endud, C. S. \& Mayamar, R. - Reactive $\&$ Functional Polymers. 50, 181-190, (2002).

29. Katz, M. A.; Cheng, C. H. \& Natch, S.; - V.S. Patent 5,879,716, (1999).

30. Kim, S. Y.; Cho, S. M.; Lee, Y. M. \& Kim, S. J. - J. Appl. Polym. Sci. 78, 1381-1391, (2000).

31. Draget, K.I. - Polym. Gels Netw. 4, 143-151, (1996).

32. El-Taher, M. A.; El-Haty, M. T. \& Hussien, T. M. - Polish J. Chem. 75, 79-91, (2001).

33. Shojaei, A. H. - J. Pharm. Pharmaceut. Sci. 1, 15-30, (1998).

34. Bodmeier, R.; Oh, K. H. \& Pramar, Y. - Drug Dev. Ind. Pharm. 15, 1475-1494, (1989).

35. Bayomi, M. A.; al-Suwayeh, S. A.; el-Helw, A. M. \& Mesnad, A. F. - Pharm. Acta Helv. 73, 187-192, (1998).

36. Ritger, P. L. \& Peppas, N. A. - J. Control. Release. 5, 37-42, (1987).

Enviado: $08 / 12 / 03$

Reenviado: 23/08/04

Aprovado: 16/09/04 